\title{
Pulmonary Protective Effects of Hyberbaric Oxygen and N-Acetylcysteine Treatment in Necrotizing Pancreatitis
}

\author{
A. BALKAN, M. BALKAN ${ }^{1}$, M. YASAR ${ }^{1}$, A. KORKMAZ ${ }^{2}$, O. ERDEM ${ }^{3}$, \\ S. KILIÇ ${ }^{4}$ O. KUTSAL ${ }^{5}$, H. BILGIC
}

Department of Pulmonary Medicine, ${ }^{1}$ Department of Surgery, ${ }^{2}$ Department of Physiology, ${ }^{3}$ Department of Pharmacology, ${ }^{4}$ Department of Epidemiology, Gulhane Military Medical Academy, Gulhane School of Medicine, Turkey and ${ }^{5}$ Department of Pathology, University of Ankara, Turkey

Received February 7, 2005

Accepted July 14, 2005

On-line available August 5, 2005

\begin{abstract}
Summary
The purpose of this study is to analyze the protective effect of combining N-acetylcysteine (NAC) and hyberbaric oxygen (HBO) treatment in the lung tissue during acute pancreatitis. Sixty Sprague-Dawley male rats were randomly divided into five groups; Group I; Control group ( $n=12$ ), Group II; pancreatitis group ( $n=12)$, Group III; pancreatitis + NAC treatment group $(n=12)$, Group IV; pancreatitis + HBO treatment group $(n=12)$, Group V; pancreatitis + HBO + NAC treatment group $(n=12)$. HBO was applied postoperatively for 5 days, twice a day at 2.5 fold absolute atmospheric pressure for $90 \mathrm{~min}$. Lung tissue was obtained for measuring malondialdehyde (MDA), superoxide dismutase (Cu/ZnSOD) and glutathione peroxidase (GSH-Px) levels along with histopathological tissue examinations. This study showed that all three treated groups (HBO alone, NAC alone and combined HBO+NAC treatment) had pulmonary protective effects during acute necrotizing pancreatitis.
\end{abstract}

Key words

Acute necrotizing pancreatitis $\bullet$ Lung injury $\bullet$ Hyperbaric oxygen $\bullet$ Reactive oxygen species

\section{Introduction}

Despite the new diagnostic and therapeutic advancements, acute pancreatitis induced ARDS (Adult Respiratory Distress Syndrome) and respiratory failure still remains an important cause of morbidity and mortality in critical ill patients. Pulmonary complications of acute pancreatitis are characterized by widespread inflammation and tissue damage due to activation of pancreatic digestive enzymes, which are usually present in inactive form in the pancreas tissue (Renner et al. 1985). Necrotic pancreatic tissue infection occurs in
$40-70 \%$ of patients and this is considered to be the most important risk factor for pulmonary fatalities from acute pancreatitis (Bassi et al. 1997).

Pancreatic enzymes may activate oxygen radicals. These reactive oxygen species (ROS) and their derivates may be activated by direct or indirect routes in acute necrotizing pancreatitis resulting in the distribution of proenzymes following destruction of acinary cells. ROS have been considered as an important factor in the pathogenesis and progress of pancreatitis and pulmonary complications (Formela et al. 1995).

Approximately $95 \%$ of molecular oxygen in 
biological systems undergoes controlled reduction through the addition of four electrons in the mitochondrial cytochrome oxidase system to form water under normal conditions. The residual molecular oxygen undergoes sequential and univalent reduction resulting in partially reduced intermediates, known as ROS such as the superoxide anion, hydrogen peroxide, and the hydroxyl radical. Along with mitochondria, other important biological sources of ROS, including xanthine oxidase and leukocytes, appear to be major sources in clinical disease states (Parks 1989). It has been shown that MDA is the breakdown product of the major chain reactions leading to oxidation of polyunsaturated fatty acids and thus serves as a reliable marker of oxidative stress. It has been well documented that reactive oxygen species (ROS) play an important role in the pathogenesis of acute pancreatitis induced by cerulein (Dabrowski et al. 2000). The histological picture of cerulein-induced pancreatitis is suggested to resemble the early phase of acute edematous pancreatitis in man.

ROS are scavenged by SOD, GSH-Px and catalase. N-acetylcysteine (NAC)-induced antioxidant activity seems to have two mechanisms: ROS scavenger activity and the capacity to support glutathione synthesis (Sala et al. 1993). The mechanism of direct inhibition of ROS in patients with acute pancreatitis is not clear, but there is evidence that the use of NAC in lung-injured patients, including ARDS, could improve the evolution of this disease (Bernard 1991, Gonzalez et al. 1996).

Hyperbaric oxygen (HBO) enhances oxygenation in the whole body. The increased tissue oxygenation promotes the growth of fibroblasts, collagen formation, angiogenesis, and the phagocytic capabilities of the hypoxic leukocytes which results in beneficial effects on wound healing. Inappropriate activation of leukocytes is responsible for the damage related to reperfusion injury. After an ischemic interval, the total injury from hypoxia, and indirect injury largely mediated by inappropriate leukocyte activation can be observed (Jain 1996). Indirect component of injury is reduced by HBO administration by preventing such activation (Oriani et al. 1996). The net effect is the sparing of marginal tissue that may otherwise be lost after ischemiareperfusion injury (Chen et al. 1998).

This study was designed to evaluate the protective effects of combining $\mathrm{HBO}$ and $\mathrm{NAC}$ in pulmonary tissue during cerulein-induced acute necrotizing pancreatitis.

\section{Methods}

All experiments were performed according to protocols approved by the Institutional Animal Use and Care Committee of Gulhane Medical Academy and were performed in accordance with the National Institutes of Health guidelines for the care and handling of animals. Sixty male Sprague-Dawley rats weighing 280 to $330 \mathrm{~g}$ were obtained from Gulhane School of Medicine Research Center (Ankara, Turkey). Before the experiment, the animals were fed standard rat chow and given water ad libitum and housed in standard cages in a climate-controlled room with an ambient temperature of $23 \pm 2{ }^{\circ} \mathrm{C}$ and a 12 -h light/dark cycles for at least 1 week.

After the stabilization period, the rats were randomly divided into five groups: Group I (Control group, $n=12$ ), Group II (Acute pancreatitis group without any treatment $n=12$ ), Group III (Acute pancreatitis group undergoing NAC treatment, $n=12$ ), Group IV (Acute pancreatitis group undergoing $\mathrm{HBO}$ treatment, $\mathrm{n}=12$ ), Group V (Acute pancreatitis group undergoing $\mathrm{HBO}$ and NAC treatment, $n=12$ ) Anesthesia was induced with ether via a mask and maintained by an intraperitoneal injection of ketamine $40 \mathrm{mg} / \mathrm{kg}$ (Ketalar, Parke-Davis and Eczacibas1, Istanbul). Laparotomy was performed through a midline incision. A micro aneurysm clip was placed around a biliopancreatic duct at its entry into the duodenum to avoid reflux of enteric contents of the duct. A 28-gauche 1/2-inch, micro-fine intravenous needle attached to a 1-ml U-40 insulin syringe (B. Braun Medical, S.A., Barcelona, Spain) was introduced into the biliopancreatic duct, and $1 \mathrm{ml} / \mathrm{kg}$ of $3 \%$ sodium taurocholate (Sigma, St Louis, MO, USA) was injected into the common biliopancreatic duct under steady manual pressure, as described by Liu et al. (1999). After the injection, the microclips were removed, and the abdomen was closed in two layers. All procedures were performed under sterile conditions. We administered HBO in a hyperbaric chamber, $6 \mathrm{~h}$ after induction of pancreatitis in group IV and V. HBO treatment lasted five days, 2 sessions per day (90 $\mathrm{min}$ ) at 2.5 fold atmospheric pressure (Chen et al. 1998). Groups I, II, III were left under normal atmospheric pressure. On the day 5, surviving animals were sacrificed by an intracardiac injection of pentobarbital $(200 \mathrm{mg} / \mathrm{kg})$. Pulmonary tissue samples were obtained from each animal. Lung tissues were stored at $-70{ }^{\circ} \mathrm{C}$. 


\section{Morphometric studies of the lung}

All lungs were examined grossly after sacrifice. Lung sections were then fixed in formalin for histologic examination. Hematoxylin and eosin staining was performed, and the stained sections were reviewed by staff pathologist who were uninformed as to the conditions of each animal. The specimens were evaluated for the presence of interstitial edema, alveolar edema, alveolar hemorrhage, and interstitial mononuclear infiltrate. Each lung specimen was given a score of 0 to 3 in each category, depending on whether the findings were absent: 0 , mild: 1 , moderate: 2 or severe: 3 .

Tissue specimens were obtained from all animal groups for determination of MDA, SOD, GSH-Px. Blood for serum amylase determinations was obtained from all animals when they were sacrificed. Hitachi 917 autoanalyzer (Boehringer Manheim, Germany) was used for the amylase assay. Amylase activity was expressed in $\mathrm{U} / \mathrm{l}$.

Plasma thiobarbituric acid reactive substance (TBARS) levels were determined by the method described previously (Schoenberg et al. 1994). Lung MDA levels were determined on erythrocyte lyte obtained after centrifugation. After the reaction of thiobarbituric acid with MDA, the reaction product was extracted in butanol and was spectrofluorometrically (excitation $532 \mathrm{~nm}$, emission $553 \mathrm{~nm}$, slit $10 \mathrm{~nm}$ ) evaluated. Tetramethoxypropane solution was used as standard. TBARS levels in the lung tissue were expressed as $\mathrm{nmol} / \mathrm{g}$.

$\mathrm{Cu} / \mathrm{Zn}$-SOD activity in pulmonary tissue was measured by the method described previously (Schoenberg et al. 1990). Each hemolyte was diluted to 1:400 with $10 \mathrm{mM}$ phosphate buffer (pH 7.0). $25 \mu \mathrm{l}$ of diluted hemolyte was mixed with $850 \mu \mathrm{l}$ of substrate solution containing $0.05 \mathrm{mmol} / \mathrm{l}$ xanthine sodium and $0.025 \mathrm{mmol} / 1 \quad$ 2-(4-iodophenol)-(4-nitrophenol)-5-nphenyltetrazolium chloride (INT) in a buffer solution containing $50 \mathrm{mmol} / 1 \mathrm{CAPS}$ and $0.94 \mathrm{mmol} / \mathrm{l}$ EDTA (pH 10.2). Then, $125 \mu$ l of xanthine oxidase ( $80 \mathrm{Ul}$ ) was added to the mixture and absorbance was followed at $505 \mathrm{~nm}$ for 3 min against air. $25 \mu 1$ of phosphate buffer or $25 \mu 1$ of various standard concentrations in place of the sample were used as blank or standard determinations. $\mathrm{Cu} / \mathrm{Zn}$-SOD levels in the pulmonary tissue were expressed as $\mathrm{U} / \mathrm{g}$.

Glutathione peroxidase (GSH-Px) activity in the pulmonary tissue was measured by the method described previously (Schoenberg et al. 1990). The reaction mixture was $50 \mathrm{mmol} / \mathrm{l}$ tris buffer ( $\mathrm{pH} 7.6$ ) containing $1 \mathrm{mmol} / 1$ of $\mathrm{Na}_{2} \mathrm{EDTA}, 2 \mathrm{mmol} / \mathrm{l}$ of reduced glutathione (GSH), $0.2 \mathrm{mmol} / \mathrm{l}$ of NADPH, $4 \mathrm{mmol} / \mathrm{l}$ of sodium azide, and $1000 \mathrm{U}$ of glutathione reductase (GR). $50 \mu 1$ of plasma and $950 \mu \mathrm{l}$ of reaction mixture, or $20 \mu 1$ of erythrocyte lysate and $980 \mu 1$ of reaction mixture were mixed and incubated for $5 \mathrm{~min}$ at $37{ }^{\circ} \mathrm{C}$. Then the reaction was initiated with $8.8 \mathrm{mmol} / 1 \mathrm{H}_{2} \mathrm{O}_{2}$ and the decrease in NADPH absorbance was followed at $340 \mathrm{~nm}$ for $3 \mathrm{~min}$. Enzyme activities were expressed as $\mathrm{U} / \mathrm{g}$ in the lung tissue.

Results are expressed as the mean \pm S.D., and the median. The significance of differences between groups were tested by Kruskal-Wallis test, Bonferroni adjusted Mann-Whitney $\mathrm{U}$ test and chi-square test. Differences were considered significant at $\mathrm{p}<0.05$. Statistical analysis was performed by using the SPSS 10.0 Statistical Package Program for Windows (SPSS Inc., Chicago, Illinois, USA).

\section{Results}

In our study, fifty-eight animals completed the experimental protocol. One animal died on the second day in group II (pancreatitis without treatment) and another in the NAC group died following pancreatitis induction. The overall results are presented in Tables 1 and 2. All lobes of the lungs were intact in all groups after 5 days. Using histopathological analysis we have observed that the lungs from groups II, III, IV, and V had alveolar edema, hemorrhage, alveolar distension and collapse and interstitial cell infiltration 5 days after injecting sodium taurocholate.

\section{Amylase}

On the 5th postoperative day, the levels of amylase in the group II $(1625 \pm 420)$ and in the group III (1310 \pm 165$),$ IV $(1220 \pm 127), \mathrm{V}(1200 \pm 150)$ were signifycantly greater than in the control group (495 \pm 85$)$ $(\mathrm{P}<0.05)$. The presence of acute pancreatitis in these groups was also confirmed by a substantial amount of fluid found in the abdomen. Pharmacological evaluation of the oxidative stress was evaluated by measuring SOD, MDA and GSH-Px activity in the lung tissue.

\section{SOD activity in lungs}

When SOD activity was measured in the lung tissues, we found that it was significantly lower in group II (pancreatitis without treatment) compared to groups 
treated with $\mathrm{NAC}, \mathrm{HBO}$ or $\mathrm{HBO}+\mathrm{NAC}(\mathrm{p}<0.05)$. SOD activity was not significantly different between the groups treated with $\mathrm{NAC}, \mathrm{HBO}$ or $\mathrm{HBO}+\mathrm{NAC}(\mathrm{p}>0.05)$ (Table 1).

\section{GSH-Px activity in lungs}

In the lung tissue, GSH-Px was significantly higher in the NAC, HBO and NAC + HBO treated groups when compared to group II (pancreatitis without treatment) $(\mathrm{p}<0.05) \quad($ Table 1$)$. In addition, GSH-Px activity of lung tissue in the $\mathrm{HBO}+\mathrm{NAC}$ group was significantly higher than in the animals treated with NAC alone $(\mathrm{p}<0.05)$ but was not different from the HBO group (Table 1).
MDA activity in lungs

In the lung tissue, we observed significantly higher MDA levels in NAC, $\mathrm{HBO}$ and $\mathrm{HBO}+\mathrm{NAC}$ groups when compared to group II (pancreatitis only) $(\mathrm{p}<0.05)$ (Table 1). Lung MDA activity significantly differed between $\mathrm{HBO}, \mathrm{NAC}$ and $\mathrm{HBO}+\mathrm{NAC}$ treatment groups $(\mathrm{p}<0.05)$ (Table 1).

\section{Histopathology scoring}

In the lung tissue, we observed significantly less edema, alveolar hemorrhage, interstitial infiltration and interstitial edema in $\mathrm{HBO}, \mathrm{NAC}$ and $\mathrm{HBO}+\mathrm{NAC}$ treatment groups compared to group II (pancreatitis without treatment) (for all $\mathrm{p}<0.05$ ). Although all three treatments improved lung protection, we did not observe any statistical differences between the groups (Table 2).

Table 1. MDA, GSH-Px and SOD in the lung of rats in particular experimental groups.

\begin{tabular}{|c|c|c|c|c|c|c|}
\hline \multirow[t]{2}{*}{ Groups } & \multicolumn{2}{|c|}{ MDA (nmol/g) } & \multicolumn{2}{|c|}{ GSH-Px (U/g) } & \multicolumn{2}{|c|}{ SOD $(U / g)$} \\
\hline & Mean \pm SD & Median & Mean \pm SD & Median & Mean \pm SD & Median \\
\hline Group I & $0.26 \pm 0.04$ & 0.25 & $254.82 \pm 5.99$ & 252 & $3220.27 \pm 289.75$ & 3241 \\
\hline Group II & $0.82 \pm 0.10$ & 0.83 & $107.25 \pm 5.14$ & 106 & $1878.50 \pm 188.10$ & 1902 \\
\hline Group III & $1.26 \pm 0.11$ & 1.24 & $149.91 \pm 26.07$ & 147 & $3043.00 \pm 866.10$ & 3017 \\
\hline Group IV & $1.46 \pm 0.07$ & 1.47 & $168.55 \pm 31.74$ & 171 & $3502.82 \pm 251.00$ & 3421 \\
\hline Group V & $1.55 \pm 0.09$ & 1.58 & $175.17 \pm 24.70$ & 176 & $3801.58 \pm 1512.6$ & 3535 \\
\hline$p(I I v s V)$ & \multicolumn{2}{|c|}{$<0.001$} & \multicolumn{2}{|c|}{$<0.001$} & \multicolumn{2}{|l|}{$<0.001$} \\
\hline$p(I I I v s V)$ & \multicolumn{2}{|c|}{0.002} & \multicolumn{2}{|c|}{0.037} & \multicolumn{2}{|c|}{0.190} \\
\hline$p\left(I V v_{s} V\right)$ & \multicolumn{2}{|c|}{0.027} & \multicolumn{2}{|c|}{0.449} & \multicolumn{2}{|l|}{1.000} \\
\hline
\end{tabular}

MDA: malondialdehyde, SOD: superoxide dismutase, GSH-Px: glutathione peroxidase) Group I: Control group ( $n=11$ ), Group II: Pancreatitis group $(n=12)$, Group III: Pancreatitis + NAC treatment group $(n=12)$, Group IV: Pancreatitis + HBO treatment group $(n=12)$, Group V: Pancreatitis + HBO + NAC treatment group $(n=12)$

Table 2. Comparison of pathological results of lung tissue in particular experimental groups.

\begin{tabular}{|c|c|c|c|c|c|}
\hline Lung tissue & Edema & $\begin{array}{c}\text { Alveolar } \\
\text { Hemorrhage }\end{array}$ & $\begin{array}{l}\text { Interstitial } \\
\text { Infiltration }\end{array}$ & $\begin{array}{c}\text { Interstitial } \\
\text { Edema }\end{array}$ & $\begin{array}{c}\text { Alveolar } \\
\text { Emphysema }\end{array}$ \\
\hline$p(I I v s I I I)$ & 0.002 & 0.008 & 0.010 & 0.025 & 0.174 \\
\hline$p(I I v s I V)$ & 0.001 & 0.008 & 0.005 & 0.010 & 0.074 \\
\hline$p(I I v s V)$ & $<0.001$ & 0.002 & 0.003 & 0.016 & 0.110 \\
\hline$p\left(I I I v_{s} V\right)$ & 0.501 & 0.558 & 0.549 & 0.750 & 0.265 \\
\hline$p(I V v s V)$ & 0.757 & 0.558 & 0.619 & 0.558 & 0.439 \\
\hline$p(I I I$ vs IV $)$ & 0.721 & 1.000 & 0.478 & 0.330 & 0.842 \\
\hline
\end{tabular}

Group I; Control group ( $n=12)$, Group II; Pancreatitis group $(n=12)$, Group III; Pancreatitis + NAC treatment group ( $n=12)$, Group IV; Pancreatitis + HBO treatment group $(n=12)$, Group V; Pancreatitis + HBO + NAC treatment group $(n=12)$ 


\section{Discussion}

Clinical acute pancreatitis can be present with varying degrees of severity and associated with several systemic complications. In adults, the disorder is frequently associated with acute lung injury, manifesting itself as the adult respiratory distress syndrome. Pathological findings are characterized as diffuse alveolar damage and may include alterations such as atelectasis and alveolar edema. These respiratory complications are similar to those of ARDS (Renner et al. 1985). In the progression of acute necrotizing hemorrhagic pancreatitis there is complemental activation followed by neutrophil recruitment, sequestration, and adherence to alveolar capillary endothelial cells. Lung injury appears to result from local endothelial cell injury secondary to neutrophilgenerated ROS that may be myeloperoxidase-dependent (Guice et al. 1989). Therefore, protection against oxidant injury can be provided by preventing ROS generation or accumulation in the lungs, or by increasing the pulmonary antioxidant defense mechanisms.

An increasing number of animal studies indicates that NAC plays an important role in prevention and treatment of ROS-induced lung injury (Bernard et al. 1991). A protective effect of this agent against lung endothelial cell damage in a model of acute immunological alveolitis was shown in rats with lipopolysaccharide-induced pulmonary edema (Faggioni et al. 1994). Several authors showed that NAC prevented tissue edema and endothelial permeability in most organs and tissues, including lung and pancreas, in rat model of severe acute pancreatitis (Wang et al. 1995). However, Miller et al. (1994) did not show any improvement after the use of NAC. In agreement with these findings we have also observed that NAC treatment was effective in prevention of lung complications. In our study we showed that antioxidants such as GSH-PX and SOD increased significantly in $\mathrm{HBO}+\mathrm{NAC}$ treated groups in the lungs.

Patients with ARDS show a deficiency in the reduced form of glutathione (GSH) and an increase in the oxidized form (GSSG) in the early phase of the disease (Gonzalez et al. 1996). NAC is a GSH precursor; it enhances intracellular glutathione by affecting the metabolism of cysteine, and therefore it increases the lung levels of this antioxidant molecule (Ortolani et al. 2000). In addition, NAC can also directly increase the scavenging of ROS produced by activated neutrophils such as ${ }^{\circ} \mathrm{OH}$, $\mathrm{H}_{2} \mathrm{O}_{2}, \mathrm{HOCl}$ and ${ }^{\circ} \mathrm{O}_{2}^{-}$(Gonzalez et al. 1996).
Moine et al. (2000) showed an increased activation of NF- $\mathrm{NB}$ in alveolar macrophages of patients with ARDS, suggesting that it has an important role in this syndrome. Increased levels of proinflammatory cytokines, ROS, endotoxin, and complement fragments are present in ARDS and may contribute to NF- $\kappa B$ activation. Several antioxidants such as NAC seem to participate in the inhibition of NF- $\mathrm{B}$ activation by a number of inducers. NAC also has antiapoptotic effects due to both direct action against ROS and/or the stimulated synthesis of GSH (Cotgreave 1997).

Leme et al. (2002) showed an important effect of NAC in preventing histological changes of acute lung injury induced by experimental necrohemorrhagic pancreatitits, measured by morphometric analysis of alveolar edema, hemorrhage, emphysema, interstitial edema and infiltrate.

O'Brien et al. (2005) investigated the effects of COX-2 inhibitors in pancreatitis-induced lung injury. They found that histological injury scores were improved by this treatment. Bhatia et al. (2005) showed that DLpropargylglycine decreased the histopathological findings of pancreatitis-induced lung injury. Consistent with these results, we also showed that in the treated groups, histopathological studies, such as edema, alveolar hemorrhage, interstitial infiltration, and interstitial edema were significantly decreased compared to the pancreatitis group. However, we did not observe any significant difference between the treated groups (Table 2).

Previous studies have shown that HBO is useful in the treatment of acute pancreatitis and accompanying complication of interstitial pneumonia (Chen et al. 1998). HBO significantly improved the pathological changes in the lung tissue.

We have confirmed by detecting increasing amylase activity that pancreatitis occurred in all groups except the control group. In the HBO-treated group, amylase activity was lower than in the pancreatitis group. This finding supports previous studies, which showed the protective effect of HBO in acute pancreatitis (Chen et al. 1998).

In our study, enhanced lipid peroxidation in terms of elevated MDA concentrations was present in the lung tissue of the pancreatitis group. GSH-Px and SOD levels were increased in the lung tissue of the $\mathrm{HBO}$, NAC and $\mathrm{HBO}+\mathrm{NAC}$ groups than in animals with pancreatitis only. These results suggest that pancreatitis induces an oxidative stress in the rat lung tissue. The change in SOD activity may be regarded as an indicator of increased 
ROS production occurring during the inflammatory period and may reflect the pathophysiological process of the pancreatitis-induced lung injury. We observed that treatment of pancreatitis was further improved by $\mathrm{HBO}$ due to increased levels of SOD and GSH-Px.

Oxidative stress and resultant tissue damage are the hallmarks of cell death (Norman 1998). There is increasing evidence that in certain pathological states the increasing production and/or ineffective scavenging of such reactive oxygen species may play a crucial role in tissue injury. The levels of intermediate reduction products of oxygen metabolism (i.e. superoxide, hydroxyl radical and hydrogen peroxide) are controlled by various cellular defense mechanisms consisting of enzymatic
SOD, CAT, GSH-Px and non-enzymatic scavenger components (Mates et al. 1999).

In earlier studies, Yasar et al. (2003) demonstrated that treatment with $\mathrm{HBO}$ had a protective effect in pancreatitis. Leme et al. (2002) also showed that NAC treatment could be protective against lung injury in acute pancreatitis. This study supports the idea that both $\mathrm{HBO}$ and NAC and their combination provides an acceptable tissue protection.

We conclude that although NAC, $\mathrm{HBO}$ or $\mathrm{HBO}+\mathrm{NAC}$ can protect against pancreatitis-induced acute lung injury, there is no additional benefit in combining $\mathrm{HBO}+\mathrm{NAC}$ treatment when compared to $\mathrm{NAC}$ and $\mathrm{HBO}$ treatment alone.

\section{References}

BASSI C, FALCONI M, SARTORI N, BONARA A, CALDIRON E, BUTIRINI G, SALVIA R, PEDERZOLI P: The role of surgery in the major early complications of severe acute pancreatitis. Eur J Gastroentrol Hepatol 9: $131-136,1997$.

BHATIA M, WONG FL, FU D, LAU HY, MOOCHHALA SM, MOORE PK: Role of hydrogen sulfide in acute pancreatitis and associated lung injury. FASEB J 19: 623-625, 2005.

BERNARD GR: N-acetylcysteine in experimental and clinical acute lung injury. Am J Med 91: 54S-59S, 1991.

CHEN HM, SHYR MH, UENG SW, CHEN MF: Hyperbaric oxygen therapy attenuates pancreatic microcirculatory derangement and lung edema in an acute experimental pancreatitis model in rats. Pancreas 17: 44-49, 1998.

COTGREAVE IA: Acetylcysteine pharmacological considerations and experimental and clinical applications. $A d v$ Pharmacoll 38: 205-221, 1997.

DABROWSKI A, BOGUSLOWICZ C, DABROWSKA M, TRIBILLO I, GABRYELEWICZ A: Reactive oxygen species activate mitogen-activated protein kinases in pancreatic acinar cells. Pancreas 21: 376-384, 2000.

FAGGIONI R, GATTI S, DEMITRI MT, DELGADO R, ECHTENACHER B, GNOCCHI P, HEREMANS H, GHEZZI P: Role of xanthine oxidase and reactive oxygen intermediates in LPS- and TNF-induced pulmonary edema. J Lab Clin Med 123: 394-399, 1994.

FORMELA LJ, GALLOWAY SW, KINGSORT AN: Inflammatory mediators in acute pancreatitis. Br J Surg 82: 6-13, 1995.

GONZALEZ PK, ZHUANG J, DOCTROW SR, MALFROY B, BENSON PF, MENCONI MJ, FINK MP: Role of oxidant stress in the adult respiratory distress syndrome: evaluation of a novel antioxidant strategy in a porcine model of endotoxin-induced acute lung injury. Shock 6: 23-26, 1996.

GUICE KS, OLDHAM KT, CATY MG, JOHNSON KJ, WARD PA: Neutrophil-dependent, oxygen-radical mediated lung injury associated with acute pancreatitis. Ann Surg 210: 740-747, 1989.

JAIN KK: Physical, physiological and biochemical aspects of hyperbaric oxygenation. In: Textbook of Hyperbaric Medicine. KK JAIN, R NEUBAUER, JG CORREA, EM CAMPORESI (eds), Hogrefe \& Huber Publishers, Seattle, 1996, pp 11-26.

LEME SA, LICHTENSTEIN A, ARANTES-COSTA MF, LANDUCCI T, A. MARTINS M: Acute lung injury in experimental pancreatitis in rats: pulmonary protective effects of crotapotin and N-acetylcysteine. Shock 18: 426-433, 2002.

LIU Q, DJURICIN G, ROSSI H, BEWSEY K, GATTUSO P, WEINSTEIN RA, PRINZ RA: The effect of lexipafant on bacterial translocation in acute necrotizing pancreatitis in rats. Am Surg 65: 595-603, 1999.

MATES JM, PEREZ-GOMEZ C, NUNEZ DE CASTRO I: Antioxidant enzymes and human diseases. Clin Biochem 32: 611-616, 1999. 
MILLER BJ, HENDERSON A, STRONG RW, FIELDING GA, DIMARCO AM, O'LOUGHLIN BS: Necrotizing pancreatitis operating for life. World J Surg 18: 906-911, 1994.

MOINE P, MCINTYRE R, SCHWARTZ MD, KANEKO D, SHENKAR R, LE TULZO Y, MOORE EE, ABRAHAM $\mathrm{E}$ : NF- $\mathrm{KB}$ regulatory mechanisms in alveolar macrophages from patients with acute lung respiratory distress syndrome. Shock 13: 85-91, 2000.

NORMAN J; The role of cytokines in the pathogenesis of acute pancreatitis. Am J Surg 179: 76-83, 1998.

O'BRIEN G, SHIELDS CJ, WINTER DC, DILLON JP, KIRWAN WO, REDMOND HP: Cyclooxygenase-2 plays a central role in the genesis of pancreatitis and associated lung injury. Hepatobiliary Pancreat Dis Int 4: 126$129,2005$.

ORIANI G, MICHAEL M, MARRONI A, LONGONI C: Physiology and physiopathology of hyperbaric oxygen. In: Handbook on Hyperbaric Medicine. G ORIANI, A MARRONI, F WATTEL (eds), Springer, Milan, 1996, pp 1-34.

PARKS DA: Oxygen radicals: mediators of gastrointestinal pathophysiology. Gut 30: 293-298, 1989.

RENNER I, SAVAGE WT, PANTOJA JL, RENNER VJ: Death due to acute pancreatitis in the rats: a retrospective analysis of 405 autopsy cases. Dig Dis Sci 30: 1005-1118, 1985.

SALA R, MORIGGI E, CORVASCE G, MORELLI D: Protection by N-acetylcysteine against pulmonary endothelial cell damage by oxidant injury. Eur Respir J 6: 440-446, 1993.

SCHOENBERG MH, BUCHLER M, BEGER HG: Oxygen radicals in experimental acute pancreatitis. Hepatogastroenterology 41: 313-319, 1994.

WANG XD, DENAG XM, HARALDSEN P, ANDERSON R, IHSE EL: Antioxidant and calcium blockers counteract endothelial injury induced by acute pancreatitis in rats. Scand J Gastroenterol 30: 1129-1136, 1995.

YASAR M, YILDIZ S, MAS R, DUNDAR A, YILDIRIM A, KORKMAZ A, AKAY C, KAYMAKCIOGLU N, OZISIK T, SEN D: The effect of hyperbaric oxygen treatment on oxidative stress in experimental acute necrotizing pancreatitis. Physiol Res 52: 111-116, 2003.

\section{Reprint requests}

Arzu Balkan, Department of Pulmonary Medicine, Gulhane Military Medicine Academy, Gulhane School of Medicine, Etlik, Ankara 06013, Turkey. E-mail: balkan_arzu@yahoo.com 